\title{
Essential characteristics of ethnopolitical communications
}

\author{
Shukran Suleymanova ${ }^{1}$, and Julieta Dzhanteeva ${ }^{2}$ \\ ${ }^{1}$ Russian Presidential Academy of National Economy and Public Administration (RANEPA), \\ Vernadsky Prospekt, 84, 119571 Moscow, Russia \\ ${ }^{2}$ Institute for Humanitarian Research under the Government of the Karachay-Cherkessia Republic, \\ Gorky St., 1-A, 119571 Cherkessk, Russia
}

\begin{abstract}
The article considers the communicative essence of ethnopolitics and ethnicity. Methodological approach: communication in its political meaning is analyzed as a social phenomenon, covering all aspects of subjective perception, interpretation and assimilation of information by people, all aspects of the process of establishing meaningful contacts between senders and recipients of political information and its application following the intentions of subjects. The authors define communications in the sphere of politics or political communications as meaningful and targeted actions. Results: the norms and values of particular social groups may not coincide with each other, and in this case, it is difficult to speak about the normative-value system of society. However, this allows structuring political communications by distinguishing norms, values and the corresponding political action of individuals, belonging to specific social groups-ethnic, cultural and diaspora. In this case, political communications are a set of culturally determined interactions, which characterize the presence of significant and insignificant differences in the communicating parties in relation to the power, government, party system, and methods of political participation.
\end{abstract}

\section{Introduction}

The process of rethinking theoretical and methodological approaches to the study of ethnopolitical communications is becoming more active. The issue of ethnopolitical communications acquires a special significance due to the processes of fragmentation, destruction and restructuring of identities [1]; self-determination, integration and interethnic cooperation against the background of radical social changes, the impact of new media on political processes and their mediatization, dramatic changes in the use and availability of new information and communication technologies [2-5]. The plane of intersection of "ethnopolitics" and "communication" forms the scope of "ethnopolitical communication" concept $[6,7]$.

To understand the essence of the communication process with a targeted presentation of information and an attempt to contact the recipient, one should refer to Lasswell's classic communication model, which includes the following questions regarding the transfer of the message: who, with which intention, in which situation, what are the resources? And using 
which strategy, influencing which audience, with which result? [8] Following Lasswell's logic, the structure of ethnopolitical communications should include intentions, the situational factor, resources, the strategy of the subject, the influencing effect and the result, which is important under the following basic circumstances:

- Ethnic/ethnocultural composition of communication participants, their attitude to power, resources, statuses, interests and goals;

- Specifics of the ethnopolitical communicative space and public opinion;

- Differences in the ideas of communicators about the ways of solving the ethnopolitical communicative task;

- Presence of adequate mechanisms for the presentation of ethnopolitical interests and the involvement of the multicultural community in communication with the authorities;

- Information openness and accessibility of power for all actors of ethnopolitics;

- Use of ethnicity as an ideology to mobilize the ethnic community and achieve political goals;

- Use of ethnocultural and national (civil) integration potential;

- The possibility of overcoming communication barriers in the current social situation.

Each multicultural society is distinguished by a variety of forms of interaction and differentiation of ethnic pictures of the world, contributing to the specific perception of media's information messages, their selection, distribution and interpretation. The attitude of an individual to media texts serve as a criterion for evaluating nationalism. A nationalist prefers the perception and transmission of those messages that contain specific symbols of nationality, originating from a national source or expressed in a specific national language or culture code. The predominance of similar messages, images and memories, allows speaking of "extreme" nationalism [9-11]. In ethnopolitology, political and communicative processes associated with a ranking or stratification system with an uneven distribution of power and resources between ethnic communities are characterized by rivalry and are often accompanied by conflicts. On the other hand, communication allows combining the communication systems of two conflicting groups to increase their "commensurability" [6].

Ethnopolitics studies political processes caused by the ethnic factor resulting from the interaction of ethnonational ideologies, feelings, values, norms, opinions and corresponding management decisions. Ethnicity does not exist outside comparison or communication, only in the course of interaction of one ethnic group with another, it can show its peculiarity, "individuality" $[12,13]$.

Communication between nations is present even when there is no direct interaction, for example, in the form of sympathy of representatives of divided nations to each other. Another form of communication - antipathy - can take the form of intolerance with communication barriers and blocked information flows, affecting opinions and behavior. Ethnic communities with similar values and traditions are aware of each other's existence, but they do not necessarily communicate with each other $[14,15]$. Thus, ethnocommunications base on ethnic self-consciousness and a sense of ethnic origin, which are formed under the influence of the objective conditions of human life. However, to encourage the audience in modern conditions to accept broadcast information, to share some judgments, opinions or assessments, a predominantly persuasive effect is needed, which encounters powerful barriers in the form of mental counteraction exerted by the existence of group norms $[12,16]$.

\section{Methods}

The coincidence of the value-cultural matrices and the political views of communicants inclines to political interaction and the development of a coordinated solution, which is 
typical of interpersonal communications. At the intergroup and mass level, ethnopolitical communications appear as more complex, multidimensional and multidirectional interactions between speakers of different languages, cultures and political values, who compete, conflict or cooperate, having an ambiguous impact.

The authors suggest using the typology of social action compiled by Weber, based on which the communicative actions of actors of ethnopolitics can be presented in the form of 4 types [17]:

1. Purposeful and rational communicative action based on the knowledge of the ethnopolitical behavior of "others" and aimed at achieving a rationalized goal.

2. Value-oriented communicative action based on the belief in the ethnocultural value of a certain political action, regardless of its possible results. The essence of valueoriented action is not to achieve an external goal, but to communicate based on common ethnocultural values, which are the "code" of communication. Knowledge of the ethnocultural communication code is an important condition for effective communication, both in the framework of official procedures and within the ethnocultural model of communicative behavior. Given these circumstances, the authors denote this kind of communicative action not as value-rational (as in Weber), but as value-oriented.

3. The affective communicative action directly depends on the emotional state of the actor of ethnopolitics and is performed to manifest the affective mode of behavior.

4. The traditional communicative action is caused by the ethnic mentality and is manifested in sustainable models of communication under the influence of traditional norms and customs.

Ethnopolitical communications serve as a form of expression of the ethnopolitical process. The term "ethnopolitical communication" refers to the reception activity of the communicator and the recipient. It is the presence of a significant proportion of ethnocentricity in political communications that justifies the use of this term. To a certain extent, ethnomethodology, oriented towards the study of everyday "social facts" could contribute to the analysis of ethnopolitical communications and the tasks of estimating ethnicity. However, modern ethnic groups are no longer "closed systems" with specific cultural practices. Consequently, it is difficult to determine where the boundary lies, separating the practices characteristic of an ethnic group, from regional or intra-family ones.

Like any other types of social communication, ethnopolitical contacts contain "parameters of interculturality", which are manifested in the strategic design of ethnopolitical interaction, and its success is determined by tolerance - a tolerant attitude to the opinions, convictions and beliefs of the "other" in the absence of hostility. Intolerance is typical for ethnopolitical media communications. It is accompanied by the use of "language of enmity" in the media, replication of negative ethnic stereotypes, stories and myths that are differentiated according to ethnic criteria; they oppose each other and are subject to subjective value judgments by the authors of media texts and numerous commentators. This leads to conflict situations and does not contribute to the stabilization of the ethnopolitical communicative space. Achieving agreement in ethnopolitical communications is one of the prerequisites for building the foundation for the goal-setting of coexistence with "others".

The categories "us", "them" and "other" used in the process of communication between actors of ethnopolitics are markers that create communication barriers and increase the distance between communicators: identification and opposition mechanisms are "special cases of stereotyping..., used for consolidation and differentiation of societies" [18]. Even at the early stages of social development, inter-ethnic communications were reflected at the level of ethnic self-awareness and the emerging ethnic picture of the world, followed by the separation of "them" from "us" and the interaction of the political interests of ethnic 
communities [18]. Consequently, ethnopolitical communication is a specific kind of political relations, where classes, ethnic groups, social groups and individuals interacting in society, exchange and distribute political information.

\section{Results}

\subsection{Communicative status of an actor of ethnopolitics}

The subject of ethnopolitical interaction can be an actor who has any relation to ethnicity and/or up-to-date ethnopolitics. For example, mediators participating in crisis communications, as a rule, represent the neutral side and are not identified by ethnocommunicants as "us-them". The communicative status of an actor of ethnopolitics is determined not only by his or her communicative competence but also by the state of the ethnopolitical communicative space, temporal and dynamic parameters of the communicative act.

Depending on this, an actor of ethnopolitics can initially determine his or her communicative status and act as a sender, distributor, "opinion leader", mediator or recipient of ethnic information, which means mentioning, reconstructing or interpreting in media/texts of various life spheres of a certain nation, ethnos, ethnic community or ethnic group. In other words, the communicative status of a subject is determined not so much by his or her position in the sociopolitical structure of society, but rather by his or her communication activity and the effectiveness of communication. In the process of interaction, communicative status can be changed, which is typical, for example, for multimedia communications, when actors of ethnopolitics can simultaneously produce, distribute and receive information.

Sources, channels and means of communication often have ethnic/ethnocultural bases and are directly or indirectly connected with actors of ethnopolitics. Their choice is due to the ethnocultural characteristics of communicants, the availability of the use of various channels and means of communication, as well as their relevance and expediency of use in a particular multicultural community. Particular importance in ethnopolitical communications is attached to the problems of trust and tolerance. In many ways, they determine the effectiveness of communication. However, it cannot be asserted that the lack of trust casts doubts on the possibility of tolerant communicative behavior. Actors of ethnopolitics may not trust each other during communication and show a tolerant attitude. However, this does not mean that they will make a coordinated decision.

As follows from the above-stated definition, the participants of ethnopolitical communications pursue different goals, caused by the current ethnopolitical situation and related to the implementation of state ethnopolitics, the representation of ethnopolitical interests in the media, the actualization of nationalist ideology, the intensification of interethnic discourse, policy ethicization and the politicization of ethnicity. Along with cultural components, they are reflected in the ethnopolitical communicative behavior of the parties, the tolerance/intolerance of discourse, interpretation and use of ethnic information both before, during the communicative act and in the post-communication situation.

The structural composition of ethnopolitical communication is one of the types of political communication, including - institutional, material or technical and informational components. It should be noted that the institutional component is represented by a set of certain structures connected by information relations of collection, production, distribution and consumption of information, which can be open and latent in nature. Actors of ethnopolitical communications involve the government and public information structures; mass media and communications; modern and traditional institutions of civil society; latent 
actors; opinion leaders; ethnic entrepreneurs; ethnic lobbyists; a representative of an ethnic group; inter-ethnic alliances; the public.

\subsection{Discourse of ethnopolitical communications}

Ethnopolitical communications is a broader concept than inter-ethnic communications, which covers all kinds of political interactions in the ethnosphere. They are conducted in two different directions: from politics to ethnicity, and vice versa, from ethnicity to politics. A specific feature of ethnopolitical communications is the frequent disagreement of common inter-ethnic political interests at all levels of communication, due to which, it is important to pay attention to the process of preparing communicative acts, in which special significance is attached to identification of the communicative problem and target groups, the choice of a sociocultural scenario, the design of a form of ethnically projected messages and selection of the appropriate channels. As a result, the ethnic factor contributes to the generation of many communicative political practices, inter-ethnic interactions, intra-and inter-institutional interactions between state and civil structures.

In the structure of ethnopolitical communication, there is no category of "ethnic group", individual representatives or formalized structures articulate its political interests. Each of the actors can perform various roles - to be the sender, recipient or intermediary.

Thus, in matters of the regulation of ethnopolitical conflicts, political and communicative technologies are used that are not prescribed in the activities of official and corporate structures. The state uses the technology of public diplomacy. Acting as a mediator, it organizes informal dialogue between ethnopolitical elites, as a result of which the parties come to a compromise. The complex combination and interaction of structural elements, their interdependence, dynamics, frequency determine the type and results of ethnopolitical communications in a certain space-time continuum.

\section{Conclusions}

Ethnopolitical communications is a multidimensional phenomenon, existing in several states of ethnocultural reality at all levels of power relations: mass, group and interpersonal one. Certain types of communication correspond to each of these levels. At the mass level, ethnopolitical communication takes the form of socio-political events of an ethnic orientation, meetings, processions, demonstrations, congresses of peoples, commemorative practices, speeches in the media; at the group level - various public actions, performances; on interpersonal one - negotiations and meetings. It is possible to attract modern information and communication technologies practically at all levels of communication.

In the sphere of information broadcasting, ethnopolitical communications can be descending, ascending, horizontal; by the nature of the use of funds - verbal, non-verbal, para-verbal, virtual, by the nature of the use of information and personification of the participants of communication - formal and informal. Depending on the goal-setting, they can be directed to ethnic consolidation, acculturation and assimilation. According to the vector of development, they can be ethno-evolutionary, ethno-transformational and mixed. By the cratological criterion, ethnopolitical communications can be managerial. Since ethnopolitical communications involve relations according to the degree of ethnic subjectivity, various ethnic (ethno-national organizations) are of fundamental importance, influencing the authorities when making particular political decision.

Ehnic media, ethnocultural non-profit enterprises and research and production associations, national and cultural autonomies and other formalized and non-formalized structures are associated with ethnicity. Ethnopolitical communications contribute to the development of ethnic, ethnocultural, inter-ethnic and intercultural interaction, forming 
public consciousness and ethnic self-awareness. The establishment of effective ethnopolitical communications is one of the maturity indicators of civic and ethnopolitical culture, which create conditions for the interaction of actors of ethnopolitics who have shared "uncertainties", double opportunities or priorities.

On the other hand, giving each participant of a communicative act the right to interpret information, with its "conversion" into understanding, makes it possible to establish ethnic/ethnocultural boundaries of participation, when "others" are completely excluded, turning into carriers of external foreign ethnic influence. In this sense, there are "closed" communications, in which decisions significant for ethnonation are made, that can encourage it through communication to political action.

Thus, ethnopolitical communications are aimed at achieving political influence, cooperation and integration, which depend on communicative strategies and tactics of ethnopolitical actors in a particular multicultural environment and living conditions. This determines the possibility of establishing ethnopolitical contacts based on tolerant and trusting relations, without which the parties cannot build a foundation for the goal-setting of coexistence with "others".

\section{References}

1. M. Wieviorka, Sotsis: Sociological Studies, 8, 1 (2005) http://www.isras.ru/

2. M.S. Camara, Africa Media \& Democracy Journal, 1(1), 1 (2012) https://commons.erau.edu/

3. M. Borkert, K.E. Fisher, E. Yafi, The best, the worst, and the hardest to find: How people, mobiles, and social media connect migrants in (to) Europe, Social Media + Society (2018)

4. Sh.S. Suleimanova, N.L. Ryabova, New media and modern political processes, Council on inter-ethnic relations under the President of the Russian Federation (2016)

5. D. Diminescu, B. Loveluck, Journal of Migration \& Culture, 5(1), 23 (2014)

6. D.G. Ellis, Building a theory of communication and ethnopolitical conflict, Communication Monographs, 86(1), 68 (2019)

7. E. Han, Ethnopolitics, 12(1), 30 (2013)

8. H. Lasswell, Social Science Informati, Political Linguistics, 3(37), 260 (2011)

9. E.K. Jenne, F. Bieber, Ethnopolitics, 13(5), 431 (2014)

10. P. S. Gorski, G. Turkmen-Dervioglu, Annual Review of Sociology, 39(1), 193 (2013)

11. K. Jensen, P. Mouritsen, British Journal of Political Science, 49(3), 837 (2019)

12. A. Flesken, Ethnopolitics, 13(2), 159 (2014)

13. L. Vincze, J. Harwood, Studies in Communication Sciences, 15(1), 151 (2015)

14. R. Buttny, A. Hashim, Discourse \& Society, 26(2), 147 (2015)

15. P.N. Kirichek, Communicology, 4(1), 30 (2016)

16. A.D. Bertoli, International Studies Quarterly, 61(4), 835 (2017)

17. M. Weber, Basic Sociological Concepts (1990)

18. D.S. Dzhanteeva, Communicology, 6(2), 133 (2018) 